\title{
Fatigue fracture of femoral stem in total hip arthroplasty after use of ultrasound: A case report
}

\author{
Elmano de Araújo Loures, Fernanda Barros Costa, \\ Adriano Fernando Mendes Júnior, Glauco Mendonça Rocha, \\ Daniel Naya Loures
}

\begin{abstract}
Introduction: Fracture of the femoral stem is an infrequent event in the follow-up to a total hip arthroplasty (THA). The authors describe the case of a patient exposed to continuous application of ultrasound therapy that led to detachment of the stem-cement interface, followed by fatigue fracture of the femoral stem and the need for revision surgery. The aim of this report is to point out the possibility of undesirable effects in the use of therapeutic ultrasound in areas with underlying orthopedic implants. Case Report: A 66-yearold male patient with a previous diagnosis of psoriatic arthritis, underwent bilateral total hip arthroplasty five years ago due to avascular necrosis of femoral head after use of corticosteroids. After the appearance of an intermitent aching pain over the lateral aspect of the hip (greater trochanter) trochanteric
\end{abstract}

Elmano de Araújo Loures ${ }^{1}$, Fernanda Barros Costa ${ }^{2}$, Adriano Fernando Mendes Júnior ${ }^{3}$, Glauco Mendonça Rocha ${ }^{4}$, Daniel Naya Loures ${ }^{4}$

Affiliations: ${ }^{1}$ Chief of Department of Orthopedics, Hospital Universitário da Universidade Federal de Juiz de Fora, Juiz de Fora, Minas Gerais, Brazil; ${ }^{2}$ Medical student at Faculdade de Medicina da Universidade Federal de Juiz de Fora, Juiz de Fora, Minas Gerais, Brazil; ${ }^{3}$ Orthopedic surgeon at Hospital Universitário da Universidade Federal de Juiz de Fora, Juiz de Fora, Minas Gerais, Brazil; ${ }^{4}$ Orthopedic surgeon at Centro Médico Rio Branco, Juiz de Fora, Minas Gerais, Brazil.

Corresponding Author: Elmano de Araújo Loures, Av. Olegário Maciel, 297/1101, Juiz de Fora, Minas Gerais, Brazil 36015-350; Email: loures.elmano@gmail.com

Received: 16 April 2018

Accepted: 28 May 2018

Published: 21 June 2018 bursitis with insertional tendinopathy of the left gluteus minimus was diagnosed and physical therapy treatment was indicated along with non opioid analgesics. Inadvertently, he received local applications of continuous ultrasound during 23 sequential sessions over a period of 30 days, and presented sudden worsening of the pain. Radiographically, there was a fatigue fracture of the femoral stem. The treatment instituted was revision of the femoral component. Conclusion: The case describes a direct association between the use of ultrasound and fatigue fracture of the metallic material. The authors warn of the possibility of an undesirable effect of therapeutic ultrasound when applied repeatedly on a site with an underlying cemented orthopedic implant.

Keywords: Aseptic loosening, Hip arthroplasty, Ultrasound

\section{How to cite this article}

Loures EA, Costa FB, Júnior AFM, Rocha GM, Loures DN. Fatigue fracture of femoral stem in total hip arthroplasty after use of ultrasound: A case report. Int J Case Rep Images 2018;9:100923Zo1EL2018.

Article ID: 100923Zo1EL2018

$$
* * * * * * * * *
$$

doi: 10.5348/100923Zo1EL2018CR

\section{INTRODUCTION}

Femoral stem fracture is an infrequent event in the follow-up to a Total Hip Arthroplasty (THA) [1]. Obesity, 


\section{EDORiUM Journals}

deficiency of medial proximal femoral bone support by low femoral neck osteotomy, poor cementation, stem positioned in varus, undersized components, aseptic loosening of the prosthetic component, and traumatic events are risk factors for femoral stem fracture [1-6].

Ultrasound therapy uses high frequency waves to combat inflammation and relieve pain. Ultrasound works through two mechanisms: thermal and mechanical. The thermal component is continuous, penetrates deeply, and causes heating by molecular vibration. The mechanical component is pulsed and can act even more deeply, causing tissue expansion and contraction. Metal reflects energy and heat. Tissue heating and their reaction to this modality are controversial due to the possible deleterious effects of applying heat-generating electrotherapeutic modalities on orthopedic implant sites, and are traditionally contraindicated by various authors $[7,8]$. Other publications argue that the use of pulsed (nonthermal) and even mechanical ultrasound is safe in any situation and many physiotherapists use it without considering possible risks involved in the procedure, especially when applied to metallic implants joined with plastics and/or cement $[7,9,10]$. The association between the use of ultrasound, aseptic loosening of the implant, and subsequent fracture of the implant is not yet described in the PubMed, Lilacs, Embase, and Scielo research sources. The objective of this study is to report the case of a patient exposed to continuous applications of therapeutic ultrasound after THA, which evolved into femoral stem fracture, to describe the possible causes of the complication, and to cite its treatment. The manuscript was prepared in accordance with the CARE guidelines for case reports [11].

\section{CASE REPORT}

A 66-year-old male, businessman, with a previous diagnosis of psoriatic arthritis, a chronic user of corticosteroids with osteonecrosis of the femoral heads, underwent bilateral total hip arthroplasty. Clinical and radiological evolution was within normality, with a follow-up of 6 years on the left and 5 years on the right side, with no radiolucency lines around the components and a Harris Hip Score (HHS) [12] of 94. After the appearance of intermittent aching pain over the lateral aspect of the hip (greater trochanter) a clinical condition of trochanteric bursitis and insertional tendinopathy of the left gluteus minimus was diagnosed .The possibilities of aseptic loosening, infection, and/or mechanical failures of the implant were excluded (Figures 1 and 2). The lab tests were $\mathrm{CRP}=0,4 \mathrm{mg} / \mathrm{dl}, \mathrm{ERS}=10 \mathrm{~mm}$ / first hour and a normal leucogram. Physical therapy treatment with superficial thermotherapy and muscular strengthening was thus indicated along with non opioid analgesics. Inadvertently, he received local applications of continuous ultrasound during 23 sequential sessions over a period of 30 days. He presented a sudden change

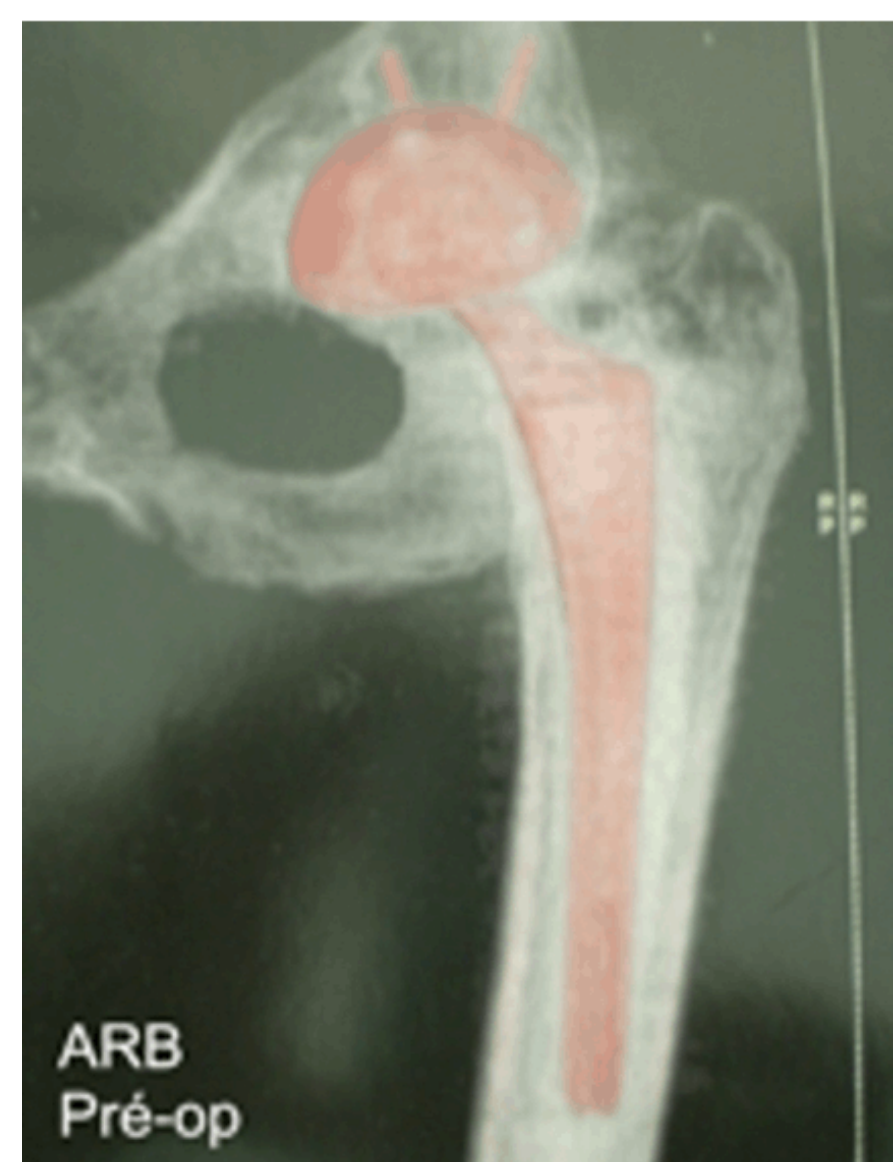

Figure 1: 3D-CT reconstruction image before use of US, without signs of loosening.

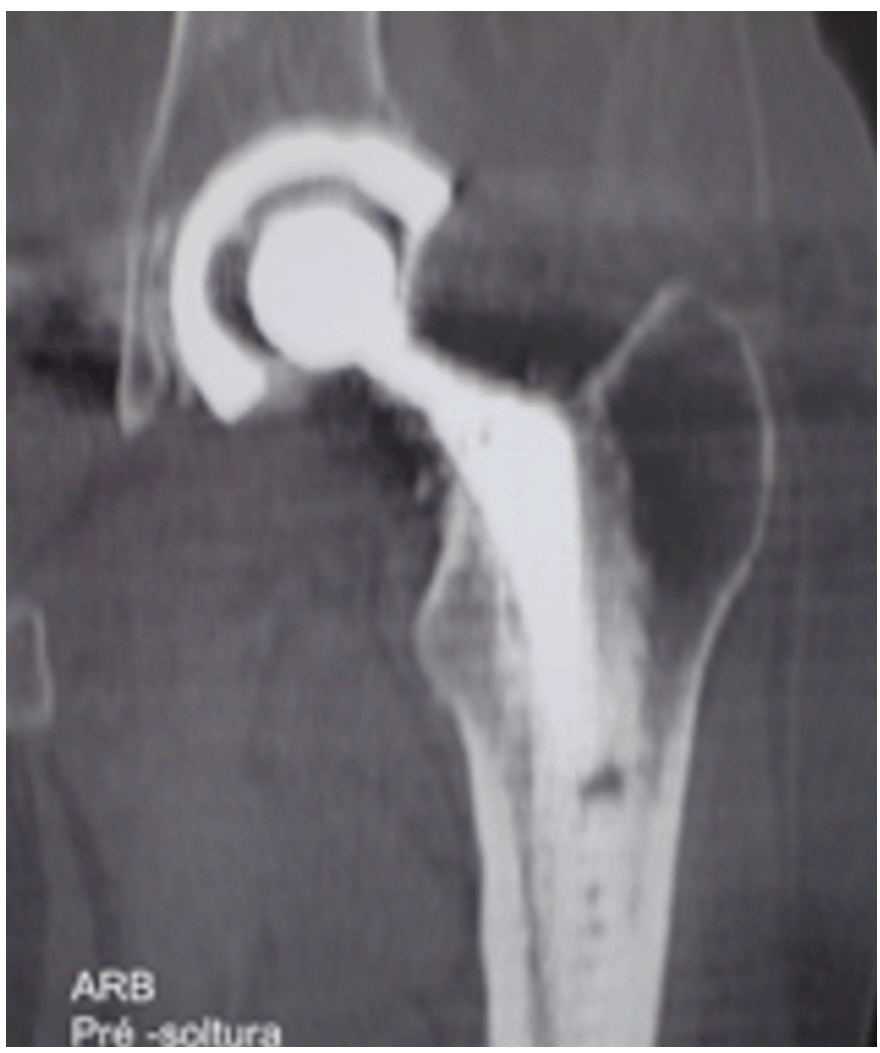

Figure 2: Coronal reformatted MPR CT image before use of US, without signs of loosening. 


\section{EDORiUM Journals}

in the characteristic of the pain that became progressively more severe and continuous in the thigh, exacerbated by walking. Radiographically, there was a clear stem-cement detachment in the femoral Gruen Zone 1 [13], without affecting the distal fixation (Figure 3), and fatigue fracture of the implant material in the region immediately distal to the detachment (Figure 4A and $4 \mathrm{~B}$ ). The treatment instituted was revision of the femoral component through extended femoral osteotomy (Figure 5 and 6) and replacement by a non-cemented distally-fixed modular stem (Figure 7). At 42 months post-revision, he was asymptomatic and had an HHS of 92 (see timeline below).

\section{DISCUSSION}

Although infrequent, femoral stem fracture in THA is a serious event in which implant revision is mandatory, requiring a major surgical procedure. In the present case, there was adequate sizing, alignment, and cementation of the implants. The presence of an identical THA in the contralateral hip served as a comparative parameter. Laboratory and imaging exams excluded the possibility of infection, aseptic loosening, or mechanical failures,

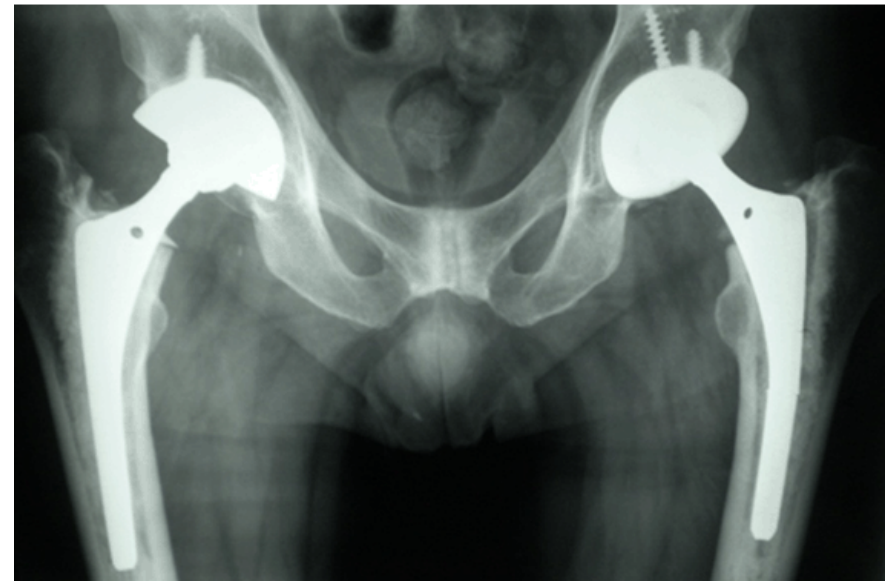

Figure 3: Bilateral hip X-ray with fracture of left side stem.

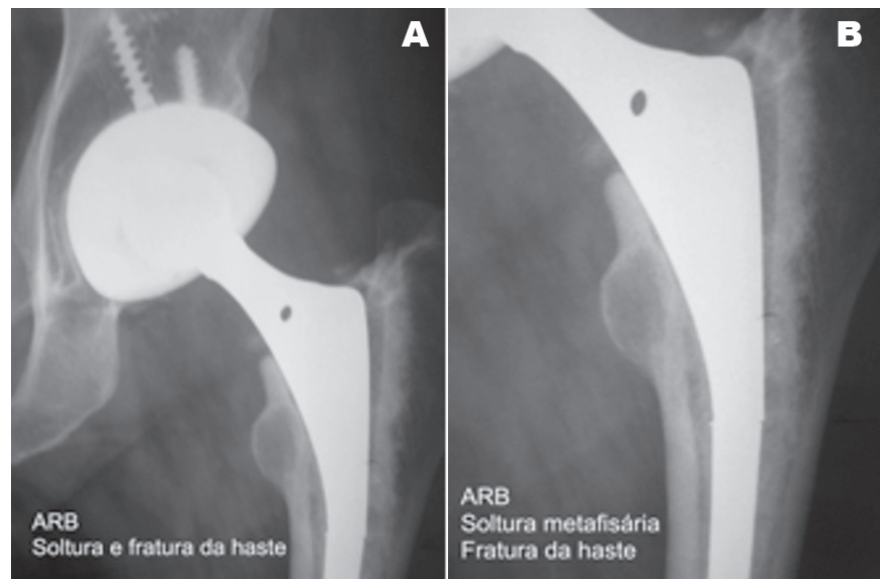

Figure 4(A and B): X-ray image with details of metaphyseal loosening and stem fracture.

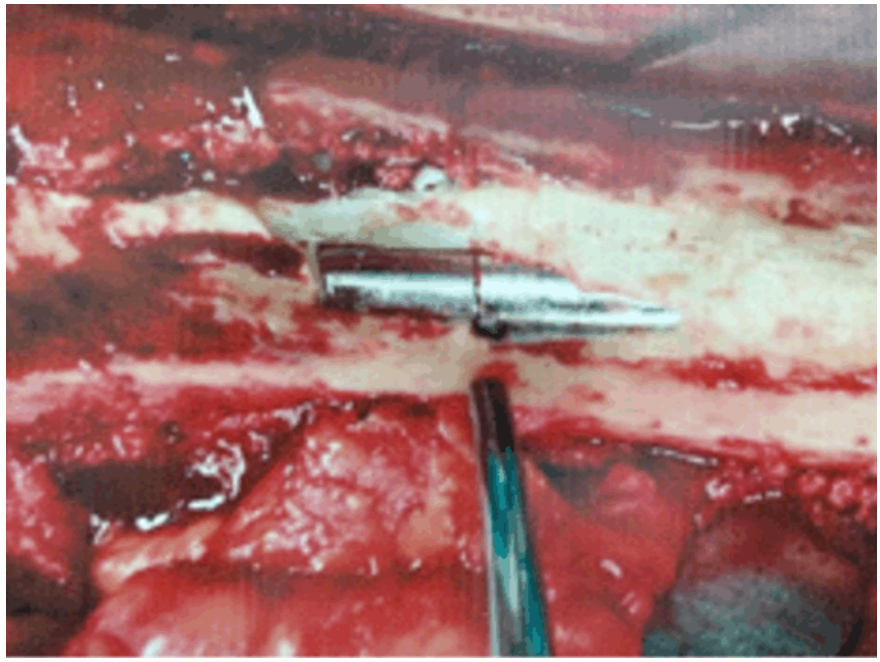

Figure 5: Intraoperative image of the revision surgery showing the broken stem.

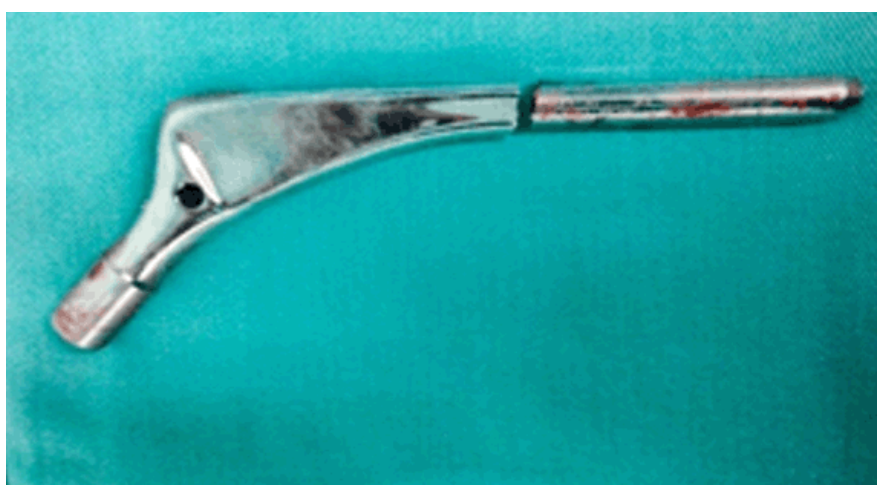

Figure 6: Detail of the fractured implant.

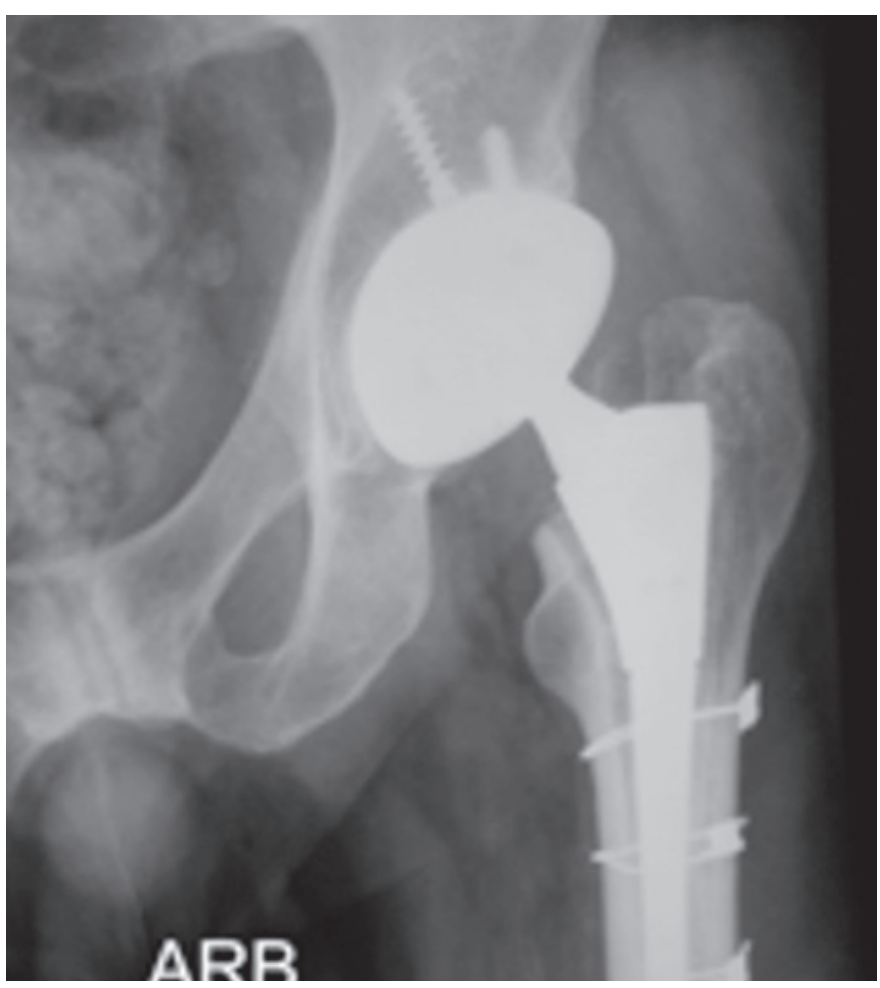

Figure 7: Post-revision X-ray appearance. 


\section{EDORiUM Journals}

and no predisposing factors to fracture were identified. Local therapy with continuous ultrasound prior to the occurrence of the implant fracture was therefore considered a unique, isolated factor and the cause of the complication.

The use of therapeutic ultrasound in patients with metal implants is usually contraindicated due to the possibility of causing thermal damage to the tissues and the surfaces in contact with the implant, with consequent loosening at the bone-cement or cementimplant interface $[9,10]$. However, this effect and its consequences are a source of controversy [8-10]. There are authors who refute this contraindication and argue that the use of therapeutic ultrasound in areas of metal implants does not promote harmful tissue and/ or implant actions $[9,10]$. Sun et al. demonstrated that components with polyethylene exhibit higher levels of temperature increase when compared to stainless steel and areas without an implant [9]. It was hypothesized that continuous ultrasound waves could be detrimental due to deep penetration into the tissue, causing microscopic vibrations. This would raise the temperature of the treated area, making the tissue warmer. The underlying metal reflects the waves differently from the surrounding local tissues and can possibly disturb and furthermore damage the metal-cement interface which have different masses and consequently different responses to the stimulus.

We highlight it as a positive aspect of the study the identification of a possible deleterious effect of therapeutic ultrasound when applied repeatedly on the site with a cemented orthopedic implant, and the subsequent fracture of the femoral stem. Also, the patient had bilateral hip arthroplasty and the unaffected side evolved without complications, it was used as a control in the hypothesis that factors innate to the individual influenced the development of the femoral stem fracture. The authors warn of the possibility, even if rare, of an undesirable effect of therapeutic ultrasound when applied repeatedly on a site with an underlying cemented orthopedic implant.

\section{CONCLUSION}

In the case described, a direct association between implant-cement interface detachment and the use of ultrasound in the overlying area was observed, with consequent loosening of the proximal half of the stem and fatigue fracture of the metallic material.

$* * * * * * * * *$

\section{Author Contributions}

Elmano de Araújo Loures - Substantial contributions to conception and design, Acquisition of data, Analysis and interpretation of data, Drafting the article, Revising it critically for important intellectual content, Final approval of the version to be published

Fernanda Barros Costa - Substantial contributions to conception and design, Acquisition of data, Analysis and interpretation of data, Drafting the article, Revising it critically for important intellectual content, Final approval of the version to be published

Adriano Fernando Mendes Júnior - Substantial contributions to conception and design, Acquisition of data, Analysis and interpretation of data, Drafting the article, Revising it critically for important intellectual content, Final approval of the version to be published Glauco Mendonça Rocha - Substantial contributions to conception and design, Acquisition of data, Analysis and interpretation of data, Drafting the article, Revising it critically for important intellectual content, Final approval of the version to be published

Daniel Naya Loures - Substantial contributions to conception and design, Acquisition of data, Analysis and interpretation of data, Drafting the article, Revising it critically for important intellectual content, Final approval of the version to be published

\section{Guarantor of Submission}

The corresponding author is the guarantor of submission.

\section{Source of Support}

None

\section{Consent Statement}

Written informed consent was obtained from the patient for publication of this case report.

\section{Conflict of Interest}

Authors declare no conflict of interest.

\section{Copyright}

(C) 2018 Elmano de Araújo Loures et al. This article is distributed under the terms of Creative Commons Attribution License which permits unrestricted use, distribution and reproduction in any medium provided the original author(s) and original publisher are properly credited. Please see the copyright policy on the journal website for more information.

\section{REFERENCES}

1. Andriacchi TP, Galante JO, Belytschko TB, Hampton S. A stress analysis of the femoral stem in total hip prostheses. J Bone Joint Surg Am 1976 Jul;58(5):61824.

2. Kishida Y, Sugano N, Ohzono K, Sakai T, Nishii T, Yoshikawa H. Stem fracture of the cementless spongy metal Lübeck hip prosthesis. J Arthroplasty 2002 Dec;17(8):1021-7.

3. Busch CA, Charles MN, Haydon CM, et al. Fractures of distally-fixed femoral stems after 
www.ijcasereportsandimages.com

revision arthroplasty. J Bone Joint Surg Br 2005 Oct;87(10):1333-6.

4. Galante JO. Causes of fractures of the femoral component in total hip replacement. J Bone Joint Surg Am 1980;62(4):670-3.

5. Bolland BJ, Wilson MJ, Howell JR, Hubble MJ, Timperley AJ, Gie GA. An analysis of reported cases of fracture of the universal exeter femoral stem prosthesis. J Arthroplasty 2017 Apr;32(4):1318-22.

6. Della Valle AG, Besksaç B, Anderson J, et al. Late fatigue fracture of a modern cemented forged cobalt chrome stem for total hip arthroplasty. J Arthroplasty 2005;20(8):1084-8.

7. Batavia M. Contraindications for superficial heat and therapeutic ultrasound: Do sources agree? Arch Phys Med Rehabil 2004 Jun;85(6):1006-12.

8. Kocaoglu B, Cabukoglu C, Ozeras N, Seyhan M, Karahan M, Yalcin S. The effect of therapeutic ultrasound on metallic implants: A study in rats. Arch Phys Med Rehabil 2011 Nov;92(11):1858-62.
9. Sun MK, Shieh J, Chen CS, Chiang H, Huang CW, Chen WS. Effects of an implant on temperature distribution in tissue during ultrasound diathermy. Ultrason Sonochem 2016 Sep;32:44-53.

10. Draper DO. Facts and misfits in ultrasound therapy: Steps to improve your treatment outcomes. Eur J Phys Rehabil Med 2014 Apr;5o(2):209-16.

11. Riley DS, Barber MS, Kienle GS, et al. CARE guidelines for case reports: Explanation and elaboration document. J Clin Epidemiol 2017 Sep;89:218-35.

12. Guimarães R, Alves D, Silva G, et al. Tradução e adaptação transcultural do instrumento de avaliação do quadril "Harris Hip Score". Acta Ortop Bras 2010;18(3):142-7.

13. Gruen TA, McNeice GM, Amstutz HC. "Modes of failure" of cemented stem-type femoral components: A radiographic analysis of loosening. Clin Orthop Relat Res 1979 Jun;(141):17-27.
Access full text article on other devices

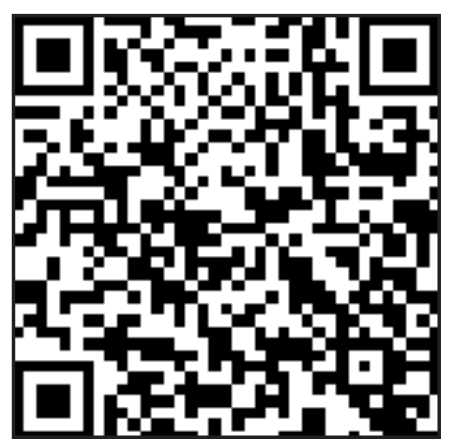

Access PDF of article on other devices

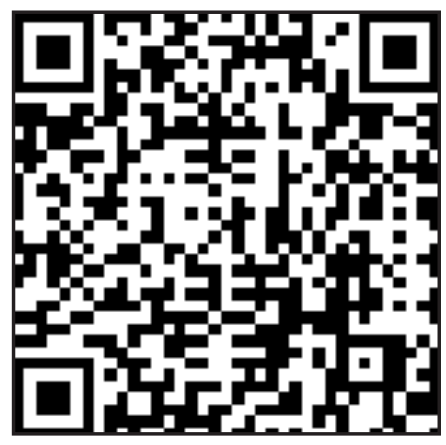

